\title{
Razões para a Casa da Gestante, Bebê e Puérpera da Maternidade-Escola Assis Chateaubriand
}

A Casa da Gestante, Bebê e Puérpera (CGBP) é uma unidade de cuidado peri-hospitalar que acolhe, orienta, cuida e acompanha gestantes e puérperas que necessitam de vigilância mais frequente de suas condições de saúde, por apresentar situação de vulnerabilidade, mas não exigem hospitalização, e que apresentem dificuldade de deslocamento frequente em decorrência da distância e/ou outros obstáculos ao deslocamento. Para o recém-nascido servirá, quando clinicamente estável, para sua recuperação nutricional, quando ainda necessite de atenção diária da equipe de saúde, mas sem a exigência da internação, ou para adaptação de seus cuidadores no manejo de cuidados específicos que serão realizados em seu domicílio. No caso das puérperas também será útil quando seu recém-nascido estiver internado em unidade de terapia intensiva ou intermediária e existir dificuldade para o deslocamento diário da sua mãe. Por essas características deve situar-se nas imediações do hospital de referência. ${ }^{1}$

As chamadas casas de espera das gestantes foram introduzidas como uma estratégia para melhorar o acesso das pacientes aos serviços hospitalares, em países do terceiro mundo. Visavam, dessa forma, a redução da morbidade e mortalidade materna e de seu neonato. ${ }^{2}$ Baseava-se na melhoria de acesso aos cuidados especializados para as gestantes, ao iniciar-se o trabalho de parto, ou ao surgirem complicações na gestação que necessitassem de internação. No entanto, em revisão da Cochrane, incluindo seis estudos retrospectivos de coorte populacional, não se encontrou evidência suficiente para recomendar essas instituições, sendo necessários novos ensaios clínicos bem controlados. ${ }^{3}$

Por que razão então instituir-se uma CGBP para a Maternidade-Escola Assis Chateaubriand?

Nossa instituição, com mais de cinquenta anos de existência, é reconhecida pelos excelentes serviços prestados à população. Não é de estranhar, portanto, que esteja sempre lotada, tanto nos nossos leitos obstétricos como nos neonatais. Esse excesso de pacientes internados acaba impactando em nossas cirurgias eletivas ginecológicas e, especialmente, em nossa emergência, por impedir novos internamentos, retardando, naquelas, procedimentos, ou, nessas, por colocar em risco pacientes que necessitariam de nossos cuidados emergenciais.

Devemos reconhecer que dentre as gestantes e puérperas internadas algumas continuam na instituição, embora não tenham mais necessidade desse internamento: são gestantes estáveis, que poderiam receber alta, mas moram muito longe e sua alta poderia colocá-las em risco; são grávidas que precisariam monitorar diariamente o bem estar fetal, mas para isso não seria necessário a hospitalização; são puérperas que têm seus filhos internados nas unidades neonatais que acabam permanecendo no hospital a espera de seus filhos, especialmente quando se considera que a alta do neonato está próxima; são recém-nascidos que estão em alojamento conjunto, que acabam, por vezes impedindo a saída da mãe, por apresentarem, por exemplo, dificuldade para amamentar.

Muitos outros exemplos poderiam ser citados. Em todos eles a existência da CGBP permitirá o acompanhamento das gestantes, das puérperas ou dos neonatos, sem colocá-los em risco. Na casa, que não deve ser confundida com abrigo ou albergue, haverá acompanhamento multiprofissional, incluindo médicos, enfermeiros, fisioterapeutas, terapeutas ocupacionais, assistentes sociais, fonoaudiólogos, psicólogos, dentre outros, e servirá de campo também para o ensino, podendo ser considerada como atividade excelente de extensão.

Finalmente, com ela, poderemos ampliar o acesso à assistência obstétrica e neonatal, contribuindo significativamente para a racionalização da utilização dos leitos hospitalares. Com ela desejamos garantir a integralidade da assistência às gestantes, puérperas e recém-nascidos, que não necessitam mais de internamento, em um ambiente seguro, acolhedor e humano, a apenas duzentos metros do hospital. Se, além de tudo isso, contribuirmos para a redução da morbidade e mortalidade materna e neonatal, fato muito difícil de ser comprovado, estaremos plenos de satisfação e realização. O tempo nos dirá!

\section{REFERÊNCIAS}

1. Brasil. Ministério da Saúde. Portaria n ${ }^{\circ}$ 1.020, de 29 de maio de 2013. Institui as diretrizes para a organização da Atenção à Saúde na Gestação de Alto Risco e define os critérios para a implantação e habilitação dos serviços de referência à Atenção à Saúde na Gestação de Alto Risco, incluída a Casa de Gestante, Bebê e Puérpera (CGBP), em conformidade com a Rede Cegonha. Brasília: Ministério da Saúde; 2013 [acesso 2017 mar 31]. Disponível em: http://bvsms.saude.gov.br/bvs/saudelegis/gm/2013/prt1020_29_05_2013.html

2. World Health Organization. Maternity waiting homes: a review of experiences. Geneva: WHO; 1996. Part two, Establishing a maternity waiting home; p. 14-21. 
3. van Lonkhuijzen L, Stekelenburg J, van Roosmalen J. Maternity waiting facilities for improving maternal and neonatal outcome in lowresource countries. Cochrane Database of Systematic Reviews. 2012; [acesso 2017 mar 31]. Disponível em: http://onlinelibrary.wiley.com/ doi/10.1002/14651858.CD006759.pub3/full

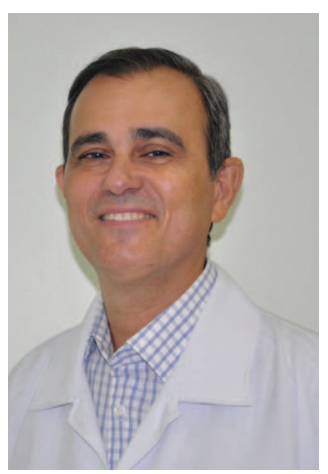

Prof. Dr Carlos Augusto Alencar Junior Departamento de Saúde Materno-Infantil Universidade Federal do Ceará

\section{Como citar:}

Alencar CA Junior. Razões para a Casa da Gestante, Bebê e Puérpera da Maternidade-Escola Assis Chateaubriand. Rev Med UFC. 2017 jan-abr;57(1):6-7. 